\title{
COMPOSTAGEM DOS RESÍDUOS ORGÂNICOS DA FCT/UNESP EM LEIRA CONVENCIONAL
}

\author{
Nome do Autor (a) Principal
}

\section{Renato Ramos da Silva Neto}

Nome (s) do Co-autor (a) (s)

Murilo Tomazini Munhoz Moya

Carlos Henrique Stocco Ortolan

Nome (s) do Orientador (a) (s)

Profa. Dra. Maria Cristina Rizk

Instituição ou Empresa

Universidade Estadual Paulista - FCT/UNESP

Instituição (s) de Fomento

E-mail de contato

renatoramos_n@hotmail.com

Palavras-chave

Compostagem; resíduos orgânicos; leira convencional

\section{INTRODUÇÃO}

A geração per capta de resíduos urbanos vem aumentando nos países em desenvolvimento, devido principalmente à rápida urbanização, ao crescimento populacional e às alterações no estilo de vida. A gestão eficaz e eficiente dos resíduos sólidos urbanos deveria ser uma prioridade nos países em desenvolvimento, pois exerce um papel muito importante na proteção do 
ambiente e da saúde pública. O gerenciamento inadequado dos resíduos urbanos, envolvendo, entre outras etapas, a geração, o armazenamento, a coleta e a disposição final deveria ser mais bem controlado, visando o bemestar comum (AGDAG, 2009).

O campus da Faculdade de Ciências e Tecnologia (FCT) da UNESP de Presidente Prudente - SP, por ser muito arborizado, apresenta uma grande produção de resíduos de poda e capina. Como o campus não possui um plano de gerenciamento para este resíduo, os mesmos são depositados em curvas de níveis no campus, ocasionando mau odor em decorrência da decomposição do material, além de atrair possíveis vetores causadores de doenças, tais como o mosquito palha e animais peçonhentos.

Outro resíduo orgânico gerado no campus é proveniente das cantinas, constituído em geral por restos de alimentos, cascas de frutas, verduras e principalmente por bagaço de laranja. Estes resíduos são destinados ao lixão municipal, porém antes são acondicionados em sacos plásticos de 100 litros e colocados em caçambas próximas às cantinas, expostos as condições climáticas ambiente e sofrendo decomposição à céu aberto.

Diante do problema da falta de um sistema de gerenciamento do resíduo orgânico produzido no campus da FCT, a compostagem, dentre as diversas soluções encontradas para o problema do lixo orgânico, é uma das mais viáveis, tendo em vista a sua capacidade de reduzir em grandes proporções (cerca de 50\%) o volume e a massa dos resíduos e possibilitar o aproveitamento do resíduo tratado como melhorador de solo.

\section{OBJETIVO GERAL}

O presente trabalho tem como objetivo geral o tratamento dos resíduos orgânicos (cantina e poda/capina) do campus da FCT/UNESP, por meio de compostagem em leira convencional.

\section{OBJETIVO ESPECÍFICO}


Os objetivos específicos do estudo envolvem a coleta e a caracterização físico-química dos resíduos; e a montagem, operação e monitoramento do sistema de compostagem e do composto orgânico produzido ao longo do experimento.

\section{METODOLOGIA}

Para a realização dos experimentos foram coletados resíduos orgânicos das cantinas, que foram selecionados previamente para a remoção de tampas de garrafas, sacos plásticos, copos plásticos, entre outros; e resíduos de poda e capina (predominantemente capina), que são dispostos em curvas de nível no campus da FCT/UNESP.

Após, os resíduos foram triturados em um triturador elétrico da marca CID35 SL, obtendo-se resíduos com diâmetro de aproximadamente $5 \mathrm{~cm}$. Os resíduos triturados foram distribuídos em camadas intercaladas sobre uma lona de 2 metros de comprimento por 1,5 metros de largura na proporção mássica de $50 \%$ de poda/capina e $50 \%$ de resíduo da cantina, obtendo-se uma leira com 0,4 metros de altura e $50 \mathrm{Kg}$ de resíduo total.

Os resíduos foram caracterizados, inicialmente, segundo KIEHL (1985) e IAL (1985) por meio dos seguintes parâmetros: pH, matéria orgânica total, resíduo mineral total, carbono orgânico, relação $\mathrm{C}: \mathrm{N}$ e umidade. Tais parâmetros foram monitorados a cada vinte dias, após o inicio do experimento de compostagem.

A cada 5 dias era feito o revolvimento manual das leiras, com o auxílio de pás, possibilitando a entrada de oxigênio no meio para melhor decomposição do material. Além disso, nos dias que a leira se encontrava muito seca era adicionada água ao composto.

A medição da temperatura nas leiras era feita diariamente, três vezes ao dia (manhã, fim da manhã e fim da tarde). As medições de temperatura foram feitas em três alturas (topo, meio e base), além de ser medida a temperatura ambiente. 
Nos dias de temperaturas baixas ou de precipitações pluviométricas, cobria-se a leira com uma lona.

\section{RESULTADOS}

A caracterização inicial da mistura de resíduos na proporção mássica de $50 \%$ de resíduos das cantinas e $50 \%$ de resíduos de poda e capina apresentou valores de nitrogênio de 1,39\% e relação C:N de 35:1, indicando que a mistura de resíduos apresentava uma boa porcentagem de nitrogênio, dentro dos valores indicados para um adequado processo de compostagem (1,2 a 1,5 \%). A relação C:N apresentou um valor um pouco acima do valor indicado para início de compostagem (30:1), porém não afetando muito o processo, pelo fato de não estar tão acima dos padrões considerados adequados.

Ao longo da compostagem, exceto no estágio final, observou-se um aumento no teor de resíduo mineral e uma conseqüente diminuição na concentração de matéria orgânica (Resíduo mineral: 9,09\% - início; 18,14\% 20 dias; 25,67\% - 40 dias; 32,65\% - 60 dias; 28,52\% - 80 dias), (Matéria orgânica: 90,90\% - início; 79,96\% - 20 dias; 74,33\% - 40 dias; 67,5\% - 60 dias; $69,26 \%$ - 80 dias). Notou-se que os valores de resíduo mineral, segundo SILVA et al. (2002) estão em uma faixa considerada boa (20 - 40\%) ou ótima (menor que 20\%).

Os valores de umidade $(47,10 \%$ - início; 69,59\% - 20 dias; 68,58\% - 40 dias; $77,60 \%$ - 60 dias; 53,44\% - 80 dias), no início encontravam-se dentro dos valores adequados, 40\% a 55\% (SILVA et al., 2002), com o tempo passaram a apresentar um excesso, e em um estágio final voltaram a apresentar valores adequados de estabilização do resíduo.

Os valores de $\mathrm{pH}$ (6,23 - início; 7,27 - 20 dias; 6,96 - 40 dias; 7,15 - 60 dias; 7,44 - 80 dias) atenderam a Instrução Normativa n. 25 de 23/07/2009 do Ministério da Agricultura, Pecuária e Abastecimento (BRASIL, 2009), que indica pH mínimo igual a 6. 
A relação C:N (35,35:1 - início; 23,15:1 - 20 dias; 23,21:1- 40 dias; 25,62:1 - 60 dias; 13,4:1 - 80 dias) encontrou-se inicialmente acima dos valores de estabilização desejáveis, no máximo 20:1 de acordo com a Instrução Normativa n. 25 de 23/07/2009 do Ministério da Agricultura, Pecuária e Abastecimento (BRASIL, 2009), porém em seu estágio final (após 80 dias) apresentou resultados desejáveis para estabilização do composto. Por fim, os valores de nitrogênio (1,39\% - início; $1,90 \%$ - 20 dias; $1,12 \%$ - 40 dias; $1,30 \%$ 60 dias; 2,87\% - 80 dias) atenderam a Instrução Normativa 25/2009, que indica valor mínimo total igual a 1.

\section{CONSIDERAÇÕES FINAIS}

Os resultados obtidos permitem concluir que o composto produzido apresentou pH adequado, redução no teor de material orgânico e aumento no teor de resíduo mineral. A relação $\mathrm{C}: \mathrm{N}$ que inicialmente apresentava valores acima do adequado para aplicação do composto em solo agrícola, com o processo da compostagem apresentou redução na relação $\mathrm{C}: \mathrm{N}$, até atingir valores ideais. A umidade apresentou um aumento durante o processo, porém no estágio final apresentou um valor muito próximo ao ideal. Com isso, pode-se concluir que o resíduo se estabilizou e atingiu condição de ser aplicado como composto orgânico em atividade agrícola, de acordo com os parâmetros da Instrução Normativa n. 25 de 23/07/2009.

\section{REFERÊNCIAS}

AGDAG, O. N., 2009, "Comparison of old and new municipal solid waste management systems in Denizli, Turkey", Waste Management, v. 29, pp. 456-464.

BRASIL, 2005, Ministério da Agricultura Pecuária e Abastecimento. Secretaria de Defesa Agropecuária. Instrução Normativa n. 23, de 31 de Agosto de 
2005. Diário Oficial da República Federativa do Brasil. Poder Executivo, Brasília.

D'AlMEIDA, M. L. O., VILHENA, A., (2000), Lixo Municipal: Manual de Gerenciamento de Resíduos. $2^{\mathrm{a}}$ edição. São Paulo: IPT/CEMPRE.

IAL - NORMAS ANALÍTICAS DO INSTITUTO ADOLFO LUTZ (1985). Métodos Químicos e Físicos para Análises de Alimentos. São Paulo: 3a edição, Editoração Débora D. Estrella Rebocho.

KIEHL, E. J, (1998), Manual de compostagem, maturação e qualidade do composto. Piracicaba.

SILVA, F. C., BERTON, R. S., CHITOLINA, J. C., et al., (2002), "Recomendações Técnicas para o Uso Agrícola do Composto de Lixo Urbano no Estado de São Paulo", Embrapa - Circular Técnica 3, pp. 1-17. 